Einführung in die Augenheilkunde. (Introduction to Ophthalmology.) BY P. A. JAENSCH. 1953. Pp. 244, 197 figs, Georg Thieme Verlag, Stuttgart. (DM 22).

This is a short, standard students' text-book of ophthalmology written in German; the first edition appeared in 1946. The arrangement follows conventional lines: a chapter on anatomy is followed by chapters on physiology, optics, and embryology, whereafter succeeding chapters deal systematically with the diseases of the eye, its adnexa, and its central nervous connections. The presentation is clear, the subject matter well chosen and concisely discussed, and the printing and illustrations excellent. For the junior student who is at home with German this short hand-book will be found admirable.

\title{
BOOKS RECEIVED
}

Strabismes et paralysies. Clinique et thérapeutique. J. Malbran. 1953. (French translation by Georges Sevrin). Pp. 693, 221 figs, 412 refs. Editions Héraly, Charleroi.

This is a translation from the original Spanish publication which was reviewed in Ophthalmic Literature (1949), 3, 3055.

\section{NOTES}

\section{International Congress of Ophthalmology Montreal and New York, 1954}

THE Treasury has granted dollar exchange for a limited number of delegates from the United Kingdom to attend the XVII International Congress in North America; allocations will be made by a joint committee appointed by the Councils of the Ophthalmological Society of the United Kingdom and the Faculty of Ophthalmologists. Intending delegates requiring dollar exchange should write to Miss Mary Morris, 45, Lincoln's Inn Fields, London, W.C.2, before March 1, 1954, after which date the Committee cannot entertain further requests for allocations.

\section{VienNa Ophthalmological Society}

THE Vienna Ophthalmological Society will celebrate their Fiftieth Anniversary on June 21-22, 1954. All ophthalmologists are cordially invited to attend. Further details will be announced at a later date.

MR. B. W. RYCROFT, F.R.C.S., has accepted an invitation from the Ophthalmological Society of South Africa to deliver a series of lectures on plastic surgery and the eye.

\section{OBITUARY}

\section{ARTHUR GREENE}

Arthur Greene died at Cromer on October 20, aged 77 years. A member of an old Irish family, he qualified in Dublin in 1898, and took his Irish fellowship 10 years later. He came to Norwich in 1903, and was the first specialist to be appointed to the staff of the Norfolk and Norwich Eye Infirmary as a full-time ophthalmic surgeon. During the first world war he saw service in France, and was for some time Ophthalmic Surgeon to the Fifth Army. He held his appointment in Norwich for 37 years, and it was largely due to his efforts that the old Eye Infirmary in Pottergate was moved to a more suitable site opposite the hospital in 1912, and was later amalgamated with the Norfolk and Norwich Hospital. 